\title{
ADUBAÇÃO NITROGENADA, DENSIDADE E ESPAÇAMENTO DE HÍBRIDOS DE MILHO EM SISTEMA PLANTIO DIRETO NA REGIÃO SUDESTE DO TOCANTINS $\left({ }^{1}\right)$
}

\author{
RENZO GARCIA VON PINHO $\left({ }^{2 *}\right)$; MARTIN REINALDO GROSS $\left({ }^{3}\right)$; ANDRÉ GUSTAVO STEOLA $\left({ }^{4}\right)$; \\ MARCELO CRUZ MENDES $\left({ }^{5}\right)$
}

\begin{abstract}
RESUMO
Entre as técnicas empregadas para a obtenção de maior produtividade de milho, o arranjamento de plantas e a época de aplicação da cobertura nitrogenada estão entre as mais importantes, associados à escolha do híbrido e do sistema de cultivo. O objetivo deste trabalho foi estudar, em sistema de plantio direto, a influência de quatro tratamentos com adubação nitrogenada, associadas a três densidades de semeadura e dois espaçamentos entre linhas, para duas cultivares de milho na Região Sudeste do Tocantins. No local, foram instalados dois experimentos em sistema de plantio direto, sendo o primeiro instalado com o espaçamento de $0,45 \mathrm{~m}$ e o segundo com $0,90 \mathrm{~m}$. Em cada experimento foram avaliados dois híbridos de milho (P 30K75 e TORK), quatro densidades de semeadura ( 55 mil, 70 mil e 85 mil plantas ha ${ }^{-1}$ ) e quatro tratamentos com adubação nitrogenada: $40 \mathrm{~kg} \mathrm{ha}^{-1}$ de $\mathrm{N}$ aplicados por ocasião da semeadura, sem nenhuma cobertura nitrogenada; $40 \mathrm{~kg} \mathrm{ha}^{-1}$ de $\mathrm{N}$ na semeadura $+120 \mathrm{~kg} \mathrm{ha}^{-1}$ de $\mathrm{N}$ aplicados em cobertura logo após a semeadura; $40 \mathrm{~kg} \mathrm{ha}^{-1}$ de $\mathrm{N}$ na semeadura + $60 \mathrm{~kg} \mathrm{ha}^{-1}$ de $\mathrm{N}$ em cobertura no estádio de 4 a 5 folhas $+60 \mathrm{~kg} \mathrm{ha}^{-1}$ de $\mathrm{N}$ em cobertura no estádio de 7 a 8 folhas; $40 \mathrm{~kg} \mathrm{ha}^{-1}$ de $\mathrm{N}$ na semeadura $+120 \mathrm{~kg} \mathrm{ha}^{-1}$ de $\mathrm{N}$ em cobertura no estádio de 6 a 7 folhas. O parcelamento da adubação nitrogenada em cobertura contribuiu para o aumento da produtividade de grãos de milho. $O$ aumento na densidade de plantas resultou no aumento da altura de plantas e da produtividade de grãos de milho. O espaçamento de $0,45 \mathrm{~m}$ proporcionou maior produtividade de grãos, independentemente da densidade de plantas e do híbrido de milho. O híbrido P 30K75 obteve maior produtividade de grãos que o híbrido TORK.
\end{abstract}

Palavras-chave: Zea mays, manejo da adubação nitrogenada, arranjo de plantas, sistema de cultivo.

\section{ABSTRACT \\ NITROGEN FERTILIZATION, SOWING RATE AND ROW SPACING IN CORN CROP UNDER NO-TILLAGE SYSTEM IN SOUTHEASTERN TOCANTINS STATE, BRAZIL}

\begin{abstract}
Among the practices and techniques employed for obtaining increased corn yield, the choice of plant arrangement and time of nitrogen topdressing are, among the most important, associated with the choice of the hybrid and cropping system. The objective of this trial was to study the influence of four nitrogen application timing, associated with three sowing rates and two row spacings, under no-tillage system, using two corn hybrids in southeastern Tocantins State. On the site, two experiments in no-tillage system were established, the first one being set up with the spacing of $0.45 \mathrm{~m}$ and the second spacing of $0.90 \mathrm{~m}$. In each experiment, two corn hybrids ( $\mathrm{P}$ $30 \mathrm{~K} 75$ and TORK), three sowing rates (55 thousand, 70 thousand and 85 thousand plants $\mathrm{ha}^{-1}$ ) and four nitrogen application timing: $40 \mathrm{~kg} \mathrm{ha}^{-1}$ of $\mathrm{N}$ applied at sowing time without nitrogen topdressing; $40 \mathrm{~kg} \mathrm{ha}^{-1}$ of $\mathrm{N}$ at sowing $+120 \mathrm{~kg} \mathrm{ha}^{-1}$ of $\mathrm{N}$ topdressed just after sowing; $40 \mathrm{~kg} \mathrm{ha}^{-1}$ of $\mathrm{N}$ at sowing $+60 \mathrm{~kg} \mathrm{ha}^{-1}$ of $\mathrm{N}$ topdressed at the stage of 4 to 5 leaves $+60 \mathrm{~kg} \mathrm{ha}^{-1}$ of $\mathrm{N}$ topdressed at the stage of 7 to 8 leaves, $40 \mathrm{~kg} \mathrm{ha}^{-1}$ of $\mathrm{N}$ at sowing $+120 \mathrm{~kg} \mathrm{ha}^{-1}$ of $\mathrm{N}$ topdressed at the stage of 6 to 7 leaves. Fractioning nitrogen application increased corn grain yield. As plant density increased, plant height and grain yield increased. Plant spacing of $0.45 \mathrm{~m}$ promoted higher grain yield regardless plant density and hybrid used. The P30K75 hybrid obtained higher grain yield than TORK hybrid.
\end{abstract}

Key words: Zea mays, management of nitrogen fertilization, plant arrangement, tillage system.

$\left({ }^{1}\right)$ Recebido para publicação em 23 de agosto de 2007 e aceito em 29 de fevereiro de 2008.

$\left({ }^{2}\right)$ Professor do Departamento de Agricultura, Universidade Federal de Lavras-UFLA, Caixa Postal 37, 37200-000 Lavras (MG). E-mail: renzo@ufla.br $\left(^{*}\right)$ Autor correspondente.

$\left({ }^{3}\right)$ MSc. Fitotecnia/UFLA. E-mail: martingross@bol.com.br

$\left({ }^{4}\right)$ MSc.Genética e Melhoramento de Plantas/UFLA. E-mail: andresteola@uol.com.br

$\left({ }^{5}\right)$ MSc.Fitotecnia/UFLA. E-mail: mcruzm@gmail.com 


\section{INTRODUÇÃO}

Sob o ponto de vista conservacionista, o sistema de plantio direto (SPD) constitui-se em um dos mais eficientes sistemas de prevenção e controle de erosão, além de diversos outros benefícios. Este sistema já é consagrado para o cultivo de milho na região da Chapada dos Gerais (Oeste da Bahia, Sudeste do Tocantins, Sul do Piauí e Sul do Maranhão) e um aspecto importante no sistema, refere-se ao manejo da adubação nitrogenada.

O sistema de preparo do solo influi na distribuição do nitrogênio através do seu perfil. Em sistema de plantio direto, a dinâmica do nitrogênio é mais influenciada, quando comparada ao sistema convencional, pois existe um aporte contínuo de resíduos vegetais, responsáveis em fornecer carbono e nitrogênio, contribuindo significativamente para a melhoria da qualidade do solo.

O nitrogênio é um dos nutrientes que proporcionam os efeitos mais espetaculares no aumento da produção de grãos na cultura do milho, como constituinte de moléculas de proteínas, enzimas, coenzimas, ácidos nucléicos e citocromos, além de sua importante função como integrante da molécula de clorofila (Bull, 1993).

O maior reservatório de $\mathrm{N}$ no solo está ligado às cadeias carbônicas, constituindo a matéria orgânica, em formas não diretamente disponíveis para as plantas (Coelho e Verlengia, 1973; Jorge, 1983; TiSDALE et al., 1993; SÁ, 1997). Portanto, para estar prontamente disponível para as plantas o $\mathrm{N}$ orgânico precisa ser transformado em formas inorgânicas ou minerais pelos processos da mineralização e imobilização através da fixação simbiótica (RAIJ, 1991; TisDale et al., 1993). Estes processos, mineralização e imobilização, são influenciados pelo tipo de resíduo cultural (relação $\mathrm{C} / \mathrm{N}$ ), manejo do resíduo (incorporado/superfície), temperatura do solo, regime de água/aeração (AulakH et al., 1991), pH e pelo teor de nutrientes no solo (AiтA, 1997).

O sistema de preparo do solo influi na distribuição do nitrogênio através do seu perfil. Assim, em sistemas com pouca movimentação do solo, como o plantio direto, há maiores acúmulos de nitrogênio na camada superficial, quando comparados aos sistemas de preparo que envolvem movimentação do solo .

Atualmente, discute-se muito sobre a época de aplicação do $\mathrm{N}$ na cultura do milho e mesmo sobre a necessidade do parcelamento para os híbridos modernos. França et al. (1994) relataram que o parcelamento indiscriminado do $\mathrm{N}$, sem levar em consideração fatores como produtividade esperada, demanda da cultura, textura do solo e outros, pode comprometer os efeitos da adubação.

YAMADA (1995) citou que o cultivo do milho tem probabilidade de resposta positiva à adubação de 30-40 kg ha ${ }^{-1}$ de $\mathrm{N}$ na semeadura, com cobertura nitrogenada feita logo após a semeadura, sendo recomendável uma segunda cobertura em solos de textura mais arenosa, visando, assim, a menores perdas e, consequentemente, maior disponibilidade de $\mathrm{N}$ para as plantas. BORGes (2003), trabalhando com solos de textura argilosa e de textura média, concluiu que, em ambas as classes do solo, a antecipação da cobertura nitrogenada, logo após a semeadura, proporcionou produtividade de grãos semelhantes às obtidas, quando foi aplicada em outros estádios fenológicos do milho.

Entre outras práticas e técnicas empregadas para a obtenção de maior produtividade de milho está a escolha da densidade ideal de plantas e do melhor arranjamento de plantas. Segundo Almeida et al. (2000), a utilização de espaçamentos menores e densidades de semeadura maiores têm demonstrado rendimentos superiores à 20\%. Assim, Resende (2003) observou que as densidades de 70 e 90 mil plantas $\mathrm{ha}^{-1}$ foram mais promissoras para produtividade de grãos, em relação a densidade de 55 mil plantas ha1 , independentemente do espaçamento utilizado. Entretanto, BorGes et al. (2006) verificou aumento na produtividade de grãos de milho, independentemente do espaçamento entre fileiras e do sistema de cultivo adotados (convencional ou direto), aplicando nitrogênio em cobertura. Este mesmo autor, em sistema de plantio direto, obteve produtividade de grãos maior quando adotou o espaçamento de 0,45 $\mathrm{m}$ entre linhas.

O aumento da densidade populacional na cultura do milho é um dos fatores que pode contribuir para a correta exploração do ambiente e do genótipo com conseqüências na maior produtividade de grãos. Entretanto, pode provocar maior competição entre plantas por nutrientes, água, luz e $\mathrm{CO}_{2}$, sendo a disponibilidade dos dois primeiros o que oferece maior limitação para o emprego de grandes populações. Segundo VianA et al. (1983), as cultivares precoces toleram maior densidade de semeadura do que as tardias, por possuírem menor estatura e massa vegetativa, proporcionando maior eficiência no aproveitamento de luz.

Os estudos de espaçamento entre fileiras, densidade de plantas e época de aplicação de nitrogênio em milho têm mostrado, freqüentemente, resultados contraditórios. Assim, é necessário intensificar as pesquisas sobre esses assuntos. 
O objetivo desse trabalho foi estudar, em sistema de plantio direto, a influência de quatro tratamentos de adubação nitrogenada, associadas a três densidades de semeadura e dois espaçamentos entre fileiras, em características agronômicas de dois híbridos de milho.

\section{MATERIAL E MÉTODOS}

Foram utilizados os híbridos comerciais de milho P30K75 de ciclo semiprecoce e o TORK que é de ciclo precoce. Os experimentos foram desenvolvidos na Fazenda Agropecuária Gross, município de Dianópolis (TO), localizada na Chapada dos Gerais, no ano agrícola 2003/2004. A precipitação pluvial ocorrida durante a condução do experimento ultrapassou os $600 \mathrm{~mm}$, valor esse suficiente para uma boa produção de milho, embora sua distribuição durante o cultivo não tenha sido uniforme. Nesse mesmo período, as temperaturas médias do ar sempre estiveram acima dos $20^{\circ} \mathrm{C}$, valor mínimo necessário para o bom desenvolvimento da planta de milho.

O solo da área onde foram instalados os experimentos sob sistema plantio direto é um Latossolo Vermelho distroférrico (LVdf) de textura média (180 $\mathrm{g} \mathrm{kg}^{-1}$ de argila) apresentando as seguintes características químicas na camada de $0-20 \mathrm{~cm}$ : $\mathrm{pH}$ em água $=5,1 ;$ M.O. $=1,0$ dag kg$^{-1} ; \mathrm{P}($ mehlich $)=29,2$ $\mathrm{mg} \mathrm{dm}{ }^{-3} ; \mathrm{K}=23,0 \mathrm{mg} \mathrm{dm}^{-3} ; \mathrm{Ca}=1,3 \mathrm{cmol}_{\mathrm{c}} \mathrm{dm}^{-3} ; \mathrm{Mg}=$ $0,4 \mathrm{cmol}_{\mathrm{c}} \mathrm{dm}^{-3} ; \mathrm{H}+\mathrm{Al}=1,7 \mathrm{cmol}_{\mathrm{c}} \mathrm{dm}^{-3} ; \mathrm{SB}=3,5 \mathrm{cmol}_{\mathrm{c}}$ $\mathrm{dm}^{-3}$; CTC $=3,5 \mathrm{cmol}_{\mathrm{c}} \mathrm{dm}^{-3}$ e V\% $=53$. Esta área vem sendo cultivada sob plantio direto há três anos com a cultura da soja.

Com base nos resultados da análise de solo e visando à obtenção de altas produtividades, conforme recomendações de RAJI et al. (1996), a adubação de plantio utilizada nos dois experimentos foi de $500 \mathrm{~kg}$ ha $^{-1}$ da formulação $8 \%(\mathrm{~N}): 28 \%\left(\mathrm{P}_{2} \mathrm{O}_{5}\right): 16 \%\left(\mathrm{~K}_{2} \mathrm{O}\right)$ mais $0,5 \%$ de zinco.

Foram instalados dois experimentos cada um com espaçamento de 0,45 e $0,90 \mathrm{~m}$, sendo a semeadura realizada manualmente em 30/11/2003. Em cada experimento, foram avaliados dois híbridos de milho (P 30K75 e TORK), três densidades de semeadura (55 mil, 70 mil e 85 mil plantas. ha $\left.{ }^{-1}\right)$ e quatro tratamentos de adubação nitrogenada (40 S + 0: $40 \mathrm{~kg} \mathrm{ha}^{-1}$ de N aplicados no sulco de semeadura, sem cobertura nitrogenada; $40 \mathrm{~S}+120$ AS: $40 \mathrm{~kg} \mathrm{ha}^{-1}$ de $\mathrm{N}$ aplicados no sulco de semeadura $+120 \mathrm{~kg} \mathrm{ha}^{-1}$ de $\mathrm{N}$ aplicados em cobertura, logo após a semeadura; $40 \mathrm{~S}+60$ (4-5 F) + 60 (7-8 F): $40 \mathrm{~kg} \mathrm{ha}^{-1}$ de $\mathrm{N}$ aplicados no sulco de semeadura $+60 \mathrm{~kg} \mathrm{ha}^{-1}$ de $\mathrm{N}$ em cobertura, no estádio de 4 a 5 folhas $+60 \mathrm{~kg} \mathrm{ha}^{-1}$ de $\mathrm{N}$ em cobertura, no estádio de 7 a 8 folhas; $40 \mathrm{~S}+120$ (6-7 F): $40 \mathrm{~kg} \mathrm{ha}^{-1}$ de $\mathrm{N}$ aplicados no sulco de semeadura $+120 \mathrm{~kg} \mathrm{ha}^{-1}$ de $\mathrm{N}$ em cobertura, no estádio de 6 a 7 folhas.

A fonte de $\mathrm{N}$ utilizada foi uréia. As adubações nitrogenadas de cobertura foram realizadas manualmente, a $20 \mathrm{~cm}$ das fileiras de plantas e incorporadas a 3,0 cm de profundidade, de acordo com a descrição dos tratamentos.

A densidade de plantio (55 mil, 70 mil e 85 mil plantas ha ${ }^{-1}$ ) foi ajustada por desbaste quando as plantas estavam com 3 a 4 folhas totalmente expandidas.

No estádio de 5 a 6 folhas totalmente expandidas, todas as parcelas receberam também 80 $\mathrm{kg} \mathrm{ha}^{-1}$ de $\mathrm{K}_{2} \mathrm{O}$ na forma de cloreto de potássio.

Cada experimento de espaçamento entre linhas de 0,45 e $0,90 \mathrm{~m}$ foi composto sob o delineamento experimental de blocos casualizados em esquema fatorial $2 \times 3 \times 4$, com três repetições, sendo os dois híbridos, as três densidades de plantio e os quatro tratamentos de adubação nitrogenada. A parcela experimental constituiu-se de quatro linhas de $5 \mathrm{~m}$ de comprimento e a área útil formada de duas linhas centrais, onde foram coletados os dados de altura de plantas, altura de inserção das espigas, produtividade de grãos e porcentagem de plantas acamadas e quebradas.

O experimento desenvolveu-se em período de temperatura favorável ao cultivo de miho, porém houve a ocorrência de excesso e má distribuição de chuvas (Figura 1).

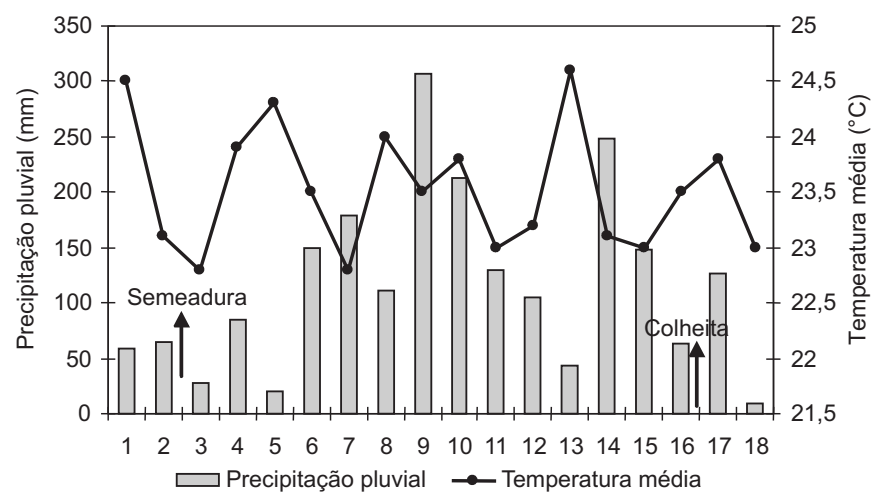

Figura 1. Temperatura média e precipitação pluvial por decêndio, de $1 .^{\circ} / 11 / 2003$ a 28/04/2004. Dados obtidos em Dianópolis (TO), 2005. 
Inicialmente foi realizada uma análise de variância individual para cada experimento (espaçamentos) e posteriormente uma análise conjunta envolvendo os dois espaçamentos, segundo BANZATTO e KRONKA (1989).

Todas as análises estatísticas foram realizadas utilizando-se o programa estatístico SISVAR (FERREIRA, 2000). Foi aplicado o teste de médias Scott-Knott, a 5\% de probabilidade, para as variáveis de natureza qualitativa (híbridos, tratamentos com adubação nitrogenada e espaçamentos) e análise de regressão para as variáveis de natureza quantitativa (densidade de plantas).

\section{RESULTADOS E DISCUSSÃO}

Os dados relativos ao efeito dos espaçamentos sobre altura de plantas e de espigas foram significativos a $(P<0,01)$. No espaçamento de $0,90 \mathrm{~m}$ obteve-se a maior altura de plantas e de espigas, sendo respectivamente 1,81 e $0,89 \mathrm{~m}$, quando comparado com o espaçamento de $0,45 \mathrm{~m}$, no qual se verificam valores de altura de planta e espiga de 1,76 e $0,85 \mathrm{~m}$. Resultados semelhantes foram observados por PenAriol et al. (2002) que, avaliando três espaçamentos entre linhas $(0,40,0,60$ e $0,80 \mathrm{~m})$, obteve maiores médias para altura de plantas no maior espaçamento entre linhas.

A cultivar TORK atingiu maior altura de plantas que a cultivar P $30 \mathrm{~K} 75$, sendo os valores, respectivamente, de 1,83 e 1,74 m.

Foram constatadas relações lineares entre a altura de plantas e a altura de inserção de espigas com a densidade de plantas (Figura 2). Pelas equações de regressão, com significância de 1\%, constataram-se, para ambas as características, que para um aumento de mil plantas na densidade, houve um acréscimo de $0,2 \mathrm{~cm}$ na altura de plantas e na inserção de espigas. Nos resultados verificados por Penariol et al. (2002), que avaliou três espaçamentos entre linhas $(0,40,0,60$ e 0,80 m) e três densidades de plantas (40, 60 e 80 mil plantas $\mathrm{ha}^{-1}$ ) ocorreram valores maiores para a altura de plantas e de inserção de espigas no maior espaçamento entre linhas e na maior densidade de plantas.

O fracionamento ou não da adubação nitrogenada em cobertura, aplicada em diversos estádios do milho não afetou significativamente sua produtividade. Todavia, foram verificadas menor altura de plantas e menor altura de espigas quando não se realizou a adubação de cobertura (Tabela 1).

Somente no híbrido P 30K75 houve diferenças na porcentagem de plantas acamadas e quebradas devido à adubação nitrogenada. Quando não foi feita a adubação de cobertura nitrogenada $(40 S+0)$, a porcentagem de plantas acamadas e quebradas foi maior. (Tabela 2).

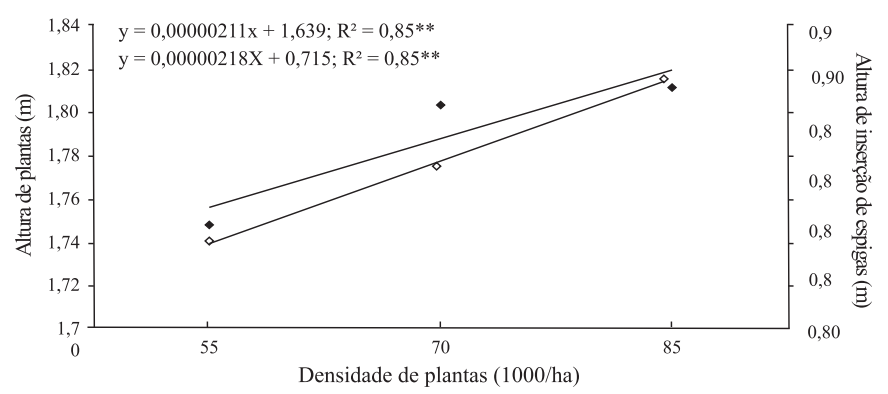

Figura 2. Representação da equação de regressão para altura de plantas e altura inserção de espigas em função das densidades de plantas de híbridos de milho P30K75 e TORK. Fazenda Agropecuária Gross, Dianópolis (TO), 2005.

Tabela 1. Altura de plantas (AP) e altura de inserção de espigas (AE), em função de tratamentos de adubação nitrogenada, considerando dois espaçamentos entre linhas, duas cultivares e três densidades de plantas. Fazenda Agropecuária Gross, Dianópolis (TO), 2005

\begin{tabular}{lcc}
\hline $\begin{array}{l}\text { Tratamentos de adubação } \\
\text { nitrogenada* }\end{array}$ & AP & AE \\
\cline { 2 - 3 } & $1,68 \mathrm{~b}$ & $0,80 \mathrm{~b}$ \\
$40 \mathrm{~S}+0$ & $1,81 \mathrm{a}$ & $0,89 \mathrm{a}$ \\
$40 \mathrm{~S}+120 \mathrm{AS}$ & $1,83 \mathrm{a}$ & $0,90 \mathrm{a}$ \\
$40 \mathrm{~S}+60(4-5 \mathrm{~F})+60(7-8 \mathrm{~F})$ & $1,83 \mathrm{a}$ & $0,88 \mathrm{a}$ \\
$40 \mathrm{~S}+120(6-7 \mathrm{~F})$ &
\end{tabular}

Médias seguidas de letras distintas diferem entre si, pelo teste de Scott-Knott $(\mathrm{P}=0,05)$.

$\left({ }^{*}\right) 40 \mathrm{~S}+120(6-7 \mathrm{~F})=40 \mathrm{~kg}$ de $\mathrm{N}$ na semeadura $+120 \mathrm{~kg}$ de $\mathrm{N}$ com $6-7$ folhas; $40 \mathrm{~S}+60(4-5 \mathrm{~F})+60(7-8 \mathrm{~F})=40 \mathrm{~kg}$ de $\mathrm{N}$ na semeadura $+60 \mathrm{~kg}$ de $\mathrm{N}$ com $5-6$ folhas $+60 \mathrm{~kg} \mathrm{~N}$ com $7-8$ folhas; $40 \mathrm{~S}+120 \mathrm{AS}=40 \mathrm{~kg}$ de $\mathrm{N}$ na semeadura $+120 \mathrm{~kg}$ de $\mathrm{N}$ após semeadura; $40 \mathrm{~S}+0=40 \mathrm{~kg}$ de $\mathrm{N}$ na semeadura.

O híbrido P 30 K75 diferenciou-se significativamente, pelo teste " $F$ ", quanto à produtividade de grãos, com $6,42 \mathrm{t} \mathrm{ha}^{-1}$, quando comparado com o híbrido TORK que produziu 6,06 t ha $^{-1}$. O espaçamento de $0,45 \mathrm{~m}$ propiciou produtividade de grãos de $6,67 \mathrm{tha}^{-1}$, enquanto o de $0,90 \mathrm{~m}$ proporcionou $5,81 \mathrm{tha}^{-1}$. Para mesma densidade de plantas, o espaçamento entre linhas de $0,45 \mathrm{~m}$ proporciona distribuição mais eqüidistante das plantas na área em relação ao de $0,90 \mathrm{~m}$. A melhor distribuição das plantas na área permite menor competição por nutrientes, água, luz e outros fatores, podendo proporcionar maiores produtividades de grãos (Sangoi, 2001). Esses resultados concordam com os verificados por BORGES 
(2003) que, em sistema de plantio direto, obteve um acréscimo de produtividade de $9,0 \%$ quando reduziu o espaçamento de 0,8 para $0,45 \mathrm{~m}$.

Tabela 2. Plantas acamadas e quebradas dos híbridos de milho, em função de tratamentos de adubação nitrogenada, considerando dois espaçamentos entre linhas e três densidades de plantas. Fazenda Agropecuária Gross, Dianópolis (TO), 2005

\begin{tabular}{llr}
\hline $\begin{array}{l}\text { Tratamentos de adubação } \\
\text { nitrogenada* }\end{array}$ & TORK & P30K75 \\
\hline & & \\
\hline $40 \mathrm{~S}+0$ & $2,55 \mathrm{aA}$ & $8,75 \mathrm{bB}$ \\
$40 \mathrm{~S}+120 \mathrm{AS}$ & $2,74 \mathrm{aA}$ & $5,26 \mathrm{aB}$ \\
$40 \mathrm{~S}+60(4-5 \mathrm{~F})+60(7-8 \mathrm{~F})$ & $1,19 \mathrm{aA}$ & $4,91 \mathrm{aB}$ \\
$40 \mathrm{~S}+120(6-7 \mathrm{~F})$ & $1,49 \mathrm{aA}$ & $3,60 \mathrm{aA}$ \\
\hline
\end{tabular}

Médias seguidas de letras distintas minúsculas na coluna diferem entre $s i$, pelo teste de Scott-Knott $(P=0,05)$ e médias seguidas de letras distintas maiúsculas na linha diferem entre si, pelo teste de "F" $(\mathrm{P}=0,01)$.

* $40 \mathrm{~S}+120(6-7 \mathrm{~F})=40 \mathrm{~kg}$ de $\mathrm{N}$ na semeadura $+120 \mathrm{~kg}$ de $\mathrm{N}$ com $6-7$ folhas; $40 \mathrm{~S}+60(4-5 \mathrm{~F})+60(7-8 \mathrm{~F})=40 \mathrm{~kg}$ de $\mathrm{N}$ na semeadura $+60 \mathrm{~kg}$ de $\mathrm{N}$ com $5-6$ folhas $+60 \mathrm{~kg} \mathrm{~N}$ com $7-8$ folhas; $40 \mathrm{~S}+$ $120 \mathrm{AS}=40 \mathrm{~kg}$ de $\mathrm{N}$ na semeadura $+120 \mathrm{~kg}$ de $\mathrm{N}$ após semeadura; $40 \mathrm{~S}+0=40 \mathrm{~kg}$ de $\mathrm{N}$ na semeadura.

A relação linear foi a melhor entre a produtividade de grãos com a densidade de plantas (Figura 3). Pela equação de regressão, com significância de $1 \%$, constata-se que para cada aumento de 1.000 plantas $\mathrm{ha}^{-1}$ na densidade, foi verificado o acréscimo de $30,4 \mathrm{~kg}$ na produtividade de grãos. Esses resultados concordam com os observados por RESENDE (2003), PenARiol et al. (2002) e Almeida et al. (2000), que obtiveram as maiores produtividades de grãos de milho utilizando as maiores densidades de plantio, respectivamente de 90, 80 e 70 mil plantas ha ${ }^{-1}$.

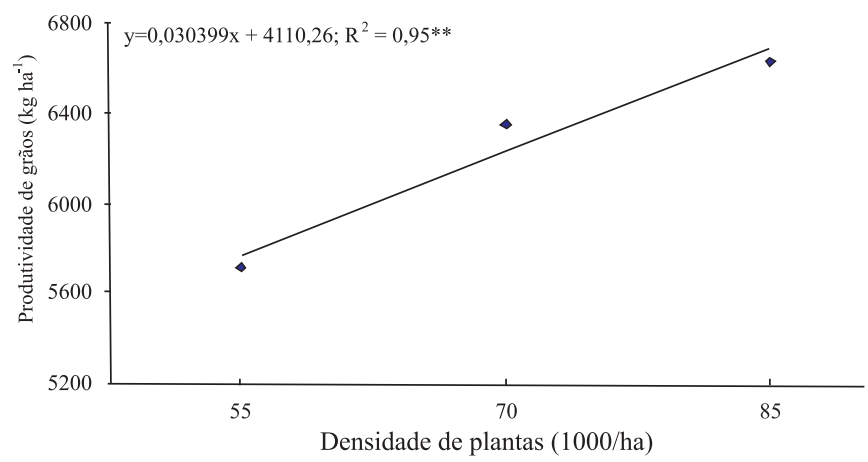

Figura 3. Representação da equação de regressão para a produtividade de grãos em função das densidades de plantas dos híbridos de milho P 30K75 e TORK. Fazenda Agropecuária Gross, Dianópolis (TO), 2005.
De acordo com os dados de precipitação pluvial (Figura 1), a fim de diminuir as perdas de $\mathrm{N}$ por lixiviação a aplicação da cobertura nitrogenada não deve ocorrer por ocasião da semeadura. Diferentemente, BORGEs (2003) verificou que a antecipação da cobertura nitrogenada para logo após a semeadura proporciona produtividades de grãos semelhantes às obtidas quando esta é aplicada em outros estádios fenológicos do milho.

A menor produtividade de grãos foi obtida sem a utilização da cobertura nitrogenada $(40 S+0)$ e as maiores com a adubação nitrogenada feita em duas aplicações $(40 \mathrm{~S}+60(4-5 \mathrm{~F})+60(7-8 \mathrm{~F}))$ ou tudo aplicado de uma única vez (40 S + 120 (6-7 F)) (Tabela 3).

Tabela 3. Produtividade de grãos em função de tratamentos de adubação nitrogenada, considerando dois espaçamentos entre linhas, duas cultivares e três densidades de plantas. Fazenda Agropecuária Gross, Dianópolis (TO), 2005

\begin{tabular}{lc}
$\begin{array}{l}\text { Tratamentos de adubação } \\
\text { nitrogenada* }\end{array}$ & $\begin{array}{c}\text { Produtividade } \\
\text { de grãos }\end{array}$ \\
\hline & $\mathrm{t} \mathrm{ha}^{-1}$ \\
$40 \mathrm{~S}+0$ & $4,99 \mathrm{c}$ \\
$40 \mathrm{~S}+120 \mathrm{AS}$ & $5,95 \mathrm{~b}$ \\
$40 \mathrm{~S}+60(4-5 \mathrm{~F})+60(7-8 \mathrm{~F})$ & $6,88 \mathrm{a}$ \\
$40 \mathrm{~S}+120(6-7 \mathrm{~F})$ & $7,13 \mathrm{a}$ \\
\hline
\end{tabular}

Médias seguidas de letras distintas diferem entre si, pelo teste de Scott-Knott $(\mathrm{P}=0,05)$

* $40 \mathrm{~S}+120(6-7 \mathrm{~F})=40 \mathrm{~kg}$ de $\mathrm{N}$ na semeadura $+120 \mathrm{~kg}$ de $\mathrm{N}$ com $6-7$ folhas; $40 \mathrm{~S}+60(4-5 \mathrm{~F})+60(7-8 \mathrm{~F})=40 \mathrm{~kg}$ de $\mathrm{N}$ na semeadura $+60 \mathrm{~kg}$ de $\mathrm{N}$ com $5-6$ folhas $+60 \mathrm{~kg} \mathrm{~N}$ com $7-8$ folhas; $40 \mathrm{~S}+$ $120 \mathrm{AS}=40 \mathrm{~kg}$ de $\mathrm{N}$ na semeadura $+120 \mathrm{~kg}$ de $\mathrm{N}$ após semeadura; $40 \mathrm{~S}+0=40 \mathrm{~kg}$ de $\mathrm{N}$ na semeadura.

Nos experimentos de Borges (2003), as precipitações pluviais foram bem distribuídas com intensidades suficientemente adequadas para o bom desenvolvimento da cultura do milho. Os resultados desse trabalho concordam com os de Sousa (1999), ao observar que a antecipação da adubação de cobertura no plantio proporciona rendimentos menores do que quando parcelada em uma ou duas vezes.

Vale ressaltar que o nitrogênio presente na solução do solo na forma de nitrato é consideravelmente lixiviado sob condições de excesso de precipitação pluvial e em solos de textura média (18\% de argila). BORTOLINI et al. (2001), cultivando milho com e sem excesso hídrico e altas doses de nitrogênio, verificaram maior perda de $\mathrm{N}$ por lixiviação quando aplicaram água em excesso na cultura (lâmina d'água $50 \%$ superior à considerada adequada), simulando os efeitos da ocorrência de chuvas intensas. 
SCHERER (2001) conclui que, em anos com precipitações pluviais pouco intensas e bem distribuídas, a adubação nitrogenada aplicada na semeadura do milho é tão eficiente quanto à aplicação parcelada; em anos com bastante chuva e alta intensidade de precipitação, o parcelamento da adubação nitrogenada é recomendável; já em anos com déficit hídrico e distribuição irregular de chuva, a adubação nitrogenada em cobertura poderá ter sua eficiência reduzida.

A textura média (18\% de argila), a alta adubação nitrogenada (160 $\left.\mathrm{kg} \mathrm{ha}^{-1}\right)$ e a alta pluviosidade na época de instalação dos experimentos, confirmam a recomendação de FANCELLI (2000), sobre o manejo da adubação nitrogenada em milho. Esse autor recomenda o parcelamento da adubação nitrogenada quando a cultura for instalada em solo com teor de argila inferior a $30 \%$; quando a época for favorável à lixiviação (período chuvoso), e quando a quantidade de nitrogênio a ser utilizada for superior a $100 \mathrm{~kg} \mathrm{ha}^{-1}$.

\section{CONCLUSÕES}

1. O parcelamento da adubação nitrogenada em cobertura contribuiu para o aumento da produtividade de grãos de milho.

2. O aumento na densidade de plantas resultou no aumento da altura de plantas e da produtividade de grãos de milho.

3. O espaçamento de $0,45 \mathrm{~m}$ proporcionou maior produtividade de grãos, independentemente da densidade de plantas e do híbrido de milho.

4. O híbrido P 30K75 obteve maior produtividade de grãos que o híbrido TORK.

\section{REFERÊNCIAS}

AITA, C. Dinâmica do nitrogênio no solo durante a decomposição de plantas de cobertura: efeito sobre a disponibilidade de nitrogênio para a cultura em sucessão. In: FRIES, M. R.; DALMOLIN, R. S. D. (Coord.). Atualização em recomendação de adubação e calagem: ênfase em plantio direto. Santa Maria: Pallotti, 1997. p. 76-111.

AULAKH, M.S.; DORAN, J.W.; WALTERS, D.T. et al. Crop residue type and placement effects on denitrification and mineralization. Soil Science Society of America Journal, Madison, v. 55, n. 4, p. 1020-1025, July/Aug. 1991.

ALMEIDA, M.L.; MEROTTO JUNIOR, A.; SANGOI, L.; ENDER, M.; GUIGDOLIN, A.F. Incremento na densidade de plantas: uma alternativa para aumentar o rendimento de grãos de milho em regiões de curta estação estival de crescimento. Ciência Rural, Santa Maria, v. 30, n. 1. p. 23-29, jan./mar. 2000.
BANZATTO, D.A.; KRONKA, S.N. Experimentação Agrícola. Jaboticabal: FUNEP, 1989. 247 p.

BORGES, I.D.; Avaliação de épocas de aplicação de cobertura nitrogenada, fontes de nitrogênio e de espaçamentos entre linhas na cultura do milho. 2003. 73 p. Dissertação (Mestrado em Fitotecnia) - Universidade Federal de Lavras, Lavras, MG.

BORGES, I.D. VON PINHO, R.G.; PEREIRA, J.L.A.R.; ALVAREZ, C.G.D. Efeito das épocas de aplicação da cobertura nitrogenada, das fontes de nitrogênio e dos espaçamentos entre fileiras na cultura do milho. Revista Ceres, Viçosa, v.53, n.305, p. 75-81, 2006.

BORTOLINI, C. G.; SILVA, P.R.F.; ARGENTA. G.; FORSTHOFER, E. L. Rendimento de grãos de milho cultivado após aveia-preta em resposta a adubação nitrogenada e regime hídrico. Pesquisa Agropecuária Brasileira, Brasília, v. 36, n. 9, p. 1101-1106, set. 2001.

BÜLL, L.T. Nutrição mineral do milho. In: BÜLL, L.T.; CANTARELLA, h. (Ed.). Cultura do milho: fatores que afetam a produtividade. Piracicaba: POTAFOS, 1993. p.63-145.

COELHO, F.S.; VERLENGIA, F. Fertilidade do solo. 2. ed. Campinas: Instituto Campineiro do Ensino Agrícola, 1973. 384 p.

FANCELLI, A.L.; DOURADO NETO, D. Produção de milho. Guaíba: E. Agropecuária, 2000. 360 p.

FERREIRA, D. F. SISVAR - Sistema de análise de variância. Versão 3.04. Lavras: UFLA, 2000.

FRANÇA, G.E.; COELHO, A.M.; RESENDE, M.; BAHIA FILHO, A.F.C. Parcelamento da adubação nitrogenada em cobertura na cultura do milho irrigado. In: CENTRO NACIONAL DE PESQUISA DE MILHO E SORGO. Relatório Anual: 1992-1993. Sete Lagoas: EMBRAPA, 1994. p. 28-30.

JORGE. J. A. Solo: manejo e adubação. 2. ed. São Paulo: Nobel, 1983. 307 p.

PENARIOL, F.G.; BORDIN, L.; COICEV, L.; FARINELLI, R.; FORNASIERI FILHO, D. Comportamento de genótipos de milho em função do espaçamento e da densidade populacional nos períodos de safrinha e safra. In: CONGRESSO NACIONAL DE MILHO E SORGO, 24., 2002, Florianópolis, SC. Anais... Florianópolis, 2002.

RAIJ, B.V. Nitrogênio. In: Fertilidade do solo e adubação. Piracicaba: Potafós, 1991. Cap. 9, p. 163-179.

RAIJ, B. van; CANTARELLA, H.; QUAGGIO, J.A.; FURLANI, A.M.C. (Ed.). Recomendações de adubação e calagem para o Estado de São Paulo. 2.ed. Campinas: Instituto Agronômico, 1996. 285 p. (Boletim Técnico, 100)

RESENDE, S.G.; Alternativas de espaçamentos entre fileiras e densidades de plantas no cultivo do milho. 2003. 55 p. Dissertação (Mestrado em Fitotecnia) - Universidade Federal de Lavras, Lavras, MG.

SÁ, J.C.M. Parâmetros para recomendação de calagem e adubação no sistema de plantio direto. In: CONFERÊNCIA ANUAL DE PLANTIO DIRETO, 2., 1997, Pato Branco. Resumos... Passo Fundo: Aldeia Norte, 1997. p. 63-81. 
SANGOI, L. Understanding plant density effects on maize growth and development: important issue to maximize grain yeld. Ciência Rural, Santa Maria, v. 31, n. 1, p. 159-168, jan./ fev., 2001.

SCHERER, E.E. Avaliação de fontes e épocas de aplicação de adubo nitrogenado na cultura do milho no sistema de plantio direto. Agropecuária Catarinense, Florianópolis, v. 14, n. 1, p. 48-53, jan./mar. 2001.

SOUZA, A.C. Parcelamento e época de aplicação de nitrogênio e seus efeitos em características agronômicas de milho. 1999. 48p. Dissertação (Mestrado em Fitotecnia) - Universidade Federal de Lavras, MG.

TISDALE, S.L.; NELSON, W.L.; BEATON, J.D.; HAVLIN. J.L. Soil fertility and fertilizers. 5. ed. New York, 1993. 634 p.

VIANA, A. C.; SILVA, A. F. da; MEDEIROS, J. B. de; CRUZ, J. C.; CORREA, L. A. Práticas culturais. In: EMPRESA DE ASSISTÊNCIA TÉCNICA E EXTENSÃO RURAL. Cultura do Milho. Brasília, 1983. p. 87-89.

YAMADA, T. Adubação nitrogenada do milho. Informações Agronômicas, Piracicaba, n. 71, p. 1-3, set. 1995. 